\title{
FORTALECIENDO CAPACIDADES INSTITUCIONALES
}

Mag. María Inés Vázquez*

En este trabajo nos proponemos reflexionar sobre algunas capacidades institucionales y analizar elementos que favorezcan su fortalecimiento, en el sentido de que esas capacidades pueden generar determinados estilos de gestión. Senge (1992) integra en su análisis sobre la gestión de centros educativos el concepto de aprendizaje institucional, presentándolo como un factor fundamental en los procesos de transformación o cambio. Señala también la necesidad de detectar la presencia de posibles "barreras" del aprendizaje que puedan estar dificultando la capacidad de respuesta que la institución alcanza ante los cambios del entorno y que el autor relaciona con aspectos de la cultura y las rutinas de trabajo en el ámbito institucional.

En este mismo sentido, Escudero (1990) afirma que los procesos de cambio que actualmente enfrentan nuestros centros educativos afectan y están afectados por la mayor o menor capacidad que la institución tiene para afrontarlos, procesarlos y transitar por ellos.

A partir de planteos como los que anteceden, resulta posible acceder a nuevos niveles de análisis de los centros educativos que permiten distinguir no sólo los componentes que constituyen las instituciones, sino también la forma en que se articulan, potencian o neutralizan. Nos permite focalizar nuestra mirada en determinadas capacidades institucionales que se manifiestan con mayor o menor grado de desarrollo en cada centro educativo de acuerdo con el tipo de interacción que se establece entre sus componentes, y que parecen representar un factor importante a la hora de evaluar el potencial institucional para encarar procesos de mejora o transformación. En este sentido Escudero, plantea la necesidad de definir estrategias de cambio que permitan desarrollar en cada centro la capacidad de diagnosticar, planificar y sostener los procesos de innovación.

Por su parte Antúnez (1994) afirma que la fortaleza de las instituciones educativas no debería evaluarse exclusivamente a partir de los éxitos alcanzados, sino también por la capacidad que demuestren tener para alcanzar nuevos logros cada vez que el entorno se los demande.

Tomando entonces a la institución educativa como unidad de análisis y ubicándola ante procesos de mejora o transformación, resulta posible analizar su comportamiento y evaluar su potencial para encarar dichos procesos, de acuerdo con la presencia o no de ciertas capacidades institucionales que pueden ser definidas como:

1- Capacidad de autoevaluación

2- Capacidad de gobernabilidad

3- Capacidad de regulación interna.

\section{1- Capacidad de autoevaluación}

La mejora escolar implica contar con la disposición por parte de los actores institucionales para emprender acciones de revisión de la realidad del centro, como paso previo y fundamental a cualquier propuesta de cambio. Partir de preguntas simples como ¿cuál es la situación en la que nos encontramos? ¿hacia dónde queremos ir? o ¿por dónde comenzar?, permiten centrar el análisis en aspectos concretos relacionados con características del centro y de las prácticas cotidianas que se desarrollan en él. 
Poner en claro los problemas a abordar y el grado de compromiso e involucramiento que los distintos miembros de la institución asumen para resolverlos, resulta un paso fundamental y previo a la definición de estrategias de acción.

El fortalecimiento de la capacidad de autoevaluación, permite al centro educativo estar en mejores condiciones para: (i) adaptarse a las variaciones del entorno, (ii) fijar puntos de partida y otros de llegada que involucren distintas porpuestas de trabajo, (iii) definir líneas de acción claras y compartidas, (iv) economizar esfuerzos y tiempo personales potencializándolos en otros colectivos.

Trabajar esta capacidad, supone -a nivel operativo- la posibilidad de llegar a determinados acuerdos básicos para comenzar a delinear una propuesta de trabajo conjunta. Entre los acuerdos a alcanzar resulta posible citar:

- La explicitación de ciertas ideas-fuerza que sirvan como referente del trabajo colectivo dentro del ámbito institucional.

- La definición y el análisis de un cierto estado de situación del que parta la propuesta de trabajo.

- La selección de problemas a trabajar.

- La definición de estrategias colectivas para su resolución, enmarcadas dentro de un lapso concreto y con la expectativa de alcanzar logros colectivos claros y posibles de evaluar.

\section{2- Capacidad de gobernabilidad}

Reconocer las dificultades que la institución plantea así como posibles vías para solucionarlas, parecería sin embargo no ser condición suficiente para implementar adecuadamente procesos de mejora. De poco vale trazar líneas de acción que luego no pueden ser llevadas a la práctica, si la institución permanece funcionando de forma desordenada o respondiendo todo el tiempo a las urgencias, sin la posibilidad de generar espacios que promuevan el aprendizaje institucional. Surge entonces como otra condición a alcanzar, el lograr un cierto clima de trabajo que habilite la reflexión desde la práctica y la construcción de nuevos escenarios desde los cuales impulsar acciones colectivas. Generar espacios que permitan ensayar modalidades alternativas de funcionamiento institucional, que inciten la creación de equipos funcionales de trabajo, la coordinación entre sectores, el establecimiento de criterios comunes y que permitan recuperar una visión global, dinámica y sistémica de la institución.

A nivel operativo, esta capacidad puede ser promovida a partir de acciones que apunten a:

- Generar espacios para el trabajo colectivo.

- Establecer momentos de clarificación que posibiliten intercambiar visiones y disipar dudas sobre las distintas propuestas de trabajo.

- Diseñar estructuras horarias que contemplen la presencia de espacios colectivos para la coordinación y el intercambio.

- Delegar tareas y responsabilidades involucrando distintos sectores del centro.

- Definir funciones y roles de acuerdo con las actividades propuestas.

- Elaborar estrategias colectivas para resolver conflictos con los que la institución se enfrenta habitualmente.

- Generar redes funcionales entre los distintos sectores que componen el centro.

16 - Universidad ORT Uruguay 


\section{3- Capacidad de regulación interna}

Independientemente de la organización interna que la unidad educativa logre consolidar, los cambios en el entorno se suceden en forma constante y dinámica. Este fenómeno lleva a que la institución necesite contar con mecanismos de regulación interna que le otorguen la posibilidad no sólo de ordenar sus prácticas, sino también de adaptarse a los cambios del contexto sin que ello afecte su normal funcionamiento.

Estos mecanismos están representados por los sistemas de evaluación e información institucional. Ambos sistemas aportan al centro insumos para el análisis, a partir del seguimiento de los procesos en marcha y de la evaluación de resultados. Mientras que los sistemas de evaluación permiten contar con información oportuna y actualizada sobre los procesos puestos en marcha en la institución, los sistemas de información son los que permiten socializarla dando accesoa ella a todos los actores involucrados. Son los que en definitiva, aportan insumos para analizar el grado de impacto que están teniendo nuestras prácticas cotidianas - y las de otros - en el ámbito institucional, permitiendo consolidar verdaderos sistemas de retroalimentación en el centro. Ambos sistemas permiten recuperar la noción de proceso, evitando que las propuestas se diluyan en el tiempo y que las prácticas colectivas terminen convirtiéndose poco a poco en la sumatoria de prácticas individuales.

La consolidación de estrategias de trabajo coordinadas representa una gran fortaleza institucional, que es en definitiva la que habilita al centro a enfrentar con otras potencialidades los procesos de mejora o transformación. Analizando esta capacidad desde un nivel operativo, pueden señalarse entre otras acciones a seguir las de:

- Fijar las metas de las actividades que se pretenden instrumentar.

- Definir indicadores e instrumentos que permitan su seguimiento y evaluación final.

- Diseñar estrategias para dar difusión a la información relevada, definiendo qué informar, a quién(es) y en qué momentos.

- Establecer rutinas de comunicación que generen redes funcionales entre los distintos sectores institucionales involucrados.

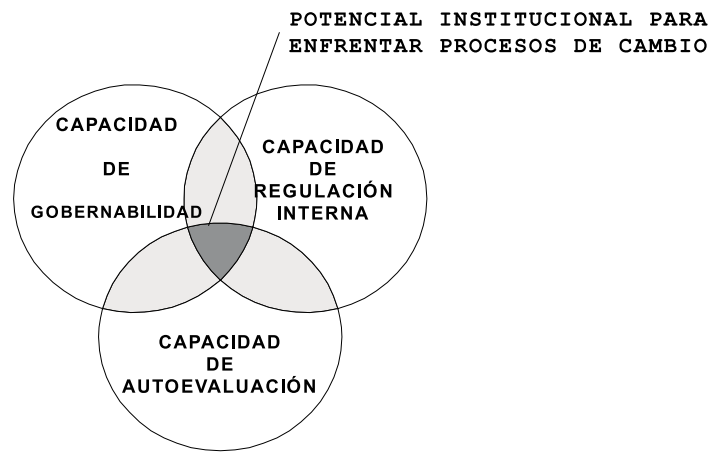

El promover desde la gestión institucional el desarrollo de las capacidades de autoevaluación, gobernabilidad y regulación interna, implica, en definitiva, integrar estrategias de revisión constante de las prácticas colectivas que conduzcan al establecimiento y consolidación de una cultura promotora del cambio. 


\section{Bibliografía}

AGUERRONDO, I. 1994 EI planeamiento como instrumento de cambio. Buenos Aires: Troquel ANTÚNEZ, S. y otros. 1996 Del proyecto educativo a la programación de aula. Barcelona: Graó. ESCUDERO MUÑOZ, J.1990 "La innovación y la organización escolar" En Pascual, R La gestión educativa ante la innovación y el Cambio. Madrid: Narcea.

GAIRÍN, J. y otros 1994 Organización de Centros Educativos. Aspectos Básicos. Barcelona: Praxis. SENGE, P 1992 La quinta disciplina. Cómo impulsar el aprendizaje en la Organización Inteligente. Barcelona: Granica.

* Magister en Investigación Educativa, Especialista en Diagnóstico Institucional. 